\title{
Profile of Dr. Ye-Guang Chen
}

Dr. Ye-Guang Chen graduated from Jiangxi University with BSc in biology in 1983, earned master's degrees at Jiangxi University in zoology in 1986 and at Fordham University, New York in cell biology in 1990, and was awarded PhD by Albert Einstein College of Medicine, New York in cell biology in 1996. After the postdoc training at Memorial Sloan-Kettering Cancer Center/Howard Hughes Medical Institute, New York, he was recruited to University of California, Riverside as assistant professor in 2000 . He moved to Tsinghua University as a professor in 2002.

His research interest has been focused on the molecular mechanisms of cell signaling, especially TGF- $\beta$ signaling and Wnt signaling. His major achievements include elucidation of the structural basis of signaling specificity in TGF- $\beta$ signaling, demonstration of the importance of subcellular localization of TGF- $\beta$ receptors in controlling their activity and stability, discovery of the regulation of Wnt signaling by autophagy. Recent work focuses on how extrinsic signals couple intrinsic epigenetic machinery and transcription factors to regulate self-renewal and differentiation of embryonic and intestinal stem cells. His findings have important implications on cell fate determination, angiogenesis, tissue fibrosis and tumorigenesis. He has published more than 140 papers in scientific journals, including Science, Nature Cell Biology, Cell Stem Cell, Molecular Cell

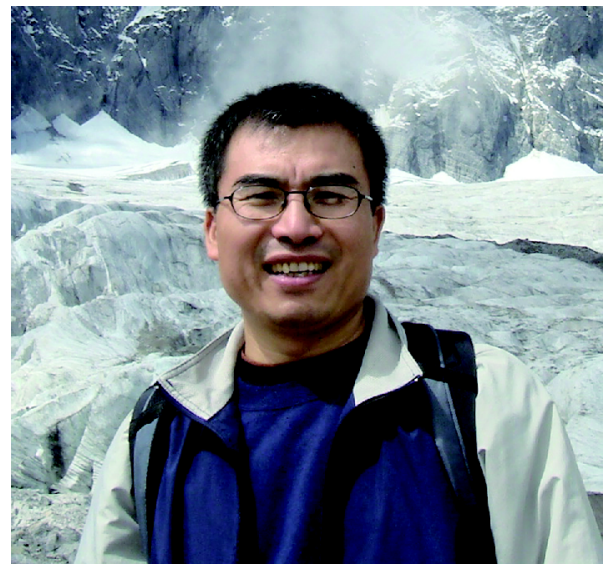

and others. His work is highly cited and well recognized by the field. He is the current president of the Chinese Society for Cell Biology. He has served on the editorial boards of several reputed journals, such as $J B C$, Cell Research, Biochemical Journal, Open Biology and some international grant review panels. He has been honored by the National Natural Science Foundation for Outstanding Young Scientist of China, Cheung Kong Scholarship and the Ho Leung Ho Lee Foundation Prize for Scientific and Technological Progress, and elected to the Chinese Academy of Sciences in 2017. 